\title{
Kajian Ilmiah dan Deteksi Adiksi Internet dan Media Sosial di Indonesia Menggunakan XGBoost
}

\author{
Rita Rismala ${ }^{\# 1}$, Ledya Novamizanti ${ }^{\# 2}$, Kurniawan Nur Ramadhani\# ${ }^{\# 3}$, Yuyun Siti Rohmah ${ }^{\# 4}$, Sabam Parjuangan ${ }^{* 5}$, \\ Dimitri Mahayana ${ }^{* 6}$ \\ ${ }^{\#}$ Universitas Telkom \\ Jl. Telekomunikasi, Terusan Buah Batu, Bandung 40257, West Java, Indonesia \\ ${ }^{1}$ ritarisetelkomuniversity.ac.id \\ ${ }^{2}$ ledyaldnetelkomuniversity.ac.id \\ ${ }^{3}$ kurniawannretelkomuniversity.ac.id \\ ${ }^{4}$ yuyunsretass.telkomuniversity.ac.id \\ *Institut Teknologi Bandung \\ Jl. Ganesa No.10, Bandung 40132, Jawa Barat, Indonesia \\ 5332200210std.stei.itb.ac.id \\ ${ }^{6}$ dimitriestei.itb.ac.id
}

\begin{abstract}
Abstrak- Internet dan media sosial telah menjadi kebutuhan pokok manusia untuk mengakses informasi, terutama di masa pandemi COVID-19 saat ini. Hal ini penting untuk dikaji karena berdampak pada perilaku dan kesehatan psikologi seseorang. Berdasarkan sudut pandang filsafat sains, adiksi internet dan media sosial di Indonesia merupakan kenyataan saintifik karena telah memenuhi kriteria falsifikasi dan dapat diuji (testable) secara empiris. Hasil survei terhadap 1980 responden, diperoleh $25,56 \%$ responden teradiksi internet dan $20,2 \%$ teradiksi media sosial. Penelitian ini juga berhasil membangun model untuk mendeteksi adiksi internet dan media sosial menggunakan XGBoost, dengan $F$-Measure sebesar $69,23 \%$ untuk adiksi internet dan $67,66 \%$ untuk adiksi media sosial. Oleh karena itu, fenomena adiksi internet dan media sosial ini perlu mendapatkan perhatian khusus agar dapat diantisipasi sejak dini.
\end{abstract}

Kata kunci - Filsafat Sains, Adiksi, Internet, Media Sosial, XGBoost

\section{PEndahuluan}

Perkembangan teknologi informasi dan komunikasi saat ini telah mengubah banyak hal dalam kehidupan manusia. Salah satu yang menjadi bagian tidak terpisahkan dengan kehidupan manusia adalah kebutuhan akan akses informasi, yang mana kebutuhan tersebut dapat terpenuhi dengan adanya internet dan media sosial [1] Peran internet semakin penting dalam bidang ekonomi, sosial, politik, budaya dan juga pendidikan apalagi saat pandemik COVID-19 seperti sekarang ini. Internet semakin mempengaruhi kehidupan umat manusia di dunia pada umumnya dan di Indonesia pada khususnya, sehingga tak dapat terbantahkan lagi teknologi ini telah mengubah peradaban dunia dengan cepat. Kecenderungan internet telah bergerak menjadi kebutuhan pokok bagi manusia [2]. Begitupun di Indonesia, pertumbuhan pengguna internet meningkat sebesar $8,9 \%$ dibanding tahun sebelumnya. Pengguna internet tahun 2019-2020 sebanyak 196.714.070,3 dari populasi Indonesia sebanyak 266.911.900 jiwa, sehingga diperoleh nilai penetrasinya adalah 73,7\% [3]. Kenaikan ini diperkirakan terus menerus bertambah seiring dengan perkembangan teknologi khususnya teknologi informasi dan komunikasi. Hal ini tentu membawa dampak positif bagi kehidupan manusia, namun tidak sedikit pula dampak negatif yang ditimbulkan apalagi jika seseorang sudah teradiksi. Sejumlah penelitian menunjukkan berbagai dampak negatif dari adiksi internet bagi kesehatan psikologi seseorang, bahkan dalam kasus yang ekstrim adiksi internet dapat menyebabkan seseorang berperilaku destruktif [4]. Oleh karena itu, deteksi adiksi internet menjadi permasalahan yang penting untuk dikaji karena hal ini berhubungan dengan pengaruhnya terhadap perilaku dan kebiasaan dalam kehidupan manusia yang mau tak mau berhadapan hampir setiap hari dengan internet.

Pada penelitian ini dibahas mengenai deteksi dan klasifikasi adiksi internet dan media sosial menggunakan metode chi-square dan algoritma XGBoost. Kedua hal tersebut dilakukan untuk mengkaji fenomena adiksi internet dan media sosial di Indonesia dari sisi kajian sains. Uji chi-square digunakan untuk mengetahui variabelvariabel yang berpengaruh terhadap adiksi internet dan media sosial. Kemudian, variabel-variabel tersebut dimodelkan dalam bentuk decision tree menggunakan algoritma XGBoost agar dapat digunakan untuk mendeteksi adiksi internet dan media sosial. Pemodelan dalam bentuk decision tree dipilih karena mudah 
diinterpretasikan dan cocok digunakan untuk data kategorikal [5], seperti data yang digunakan pada penelitian ini. Berbeda dengan algoritma decision tree standar, seperti ID3 atau C4.5, yang berbasis nilai entropy dan hanya menghasilkan satu pohon keputusan, XGBoost menerapkan konsep boosting dan tree ensemble [6]. Boosting merupakan proses untuk memperkuat classifier lemah secara iteratif sehingga semakin lama classifier menjadi semakin tinggi performansinya, sedangkan tree ensemble merupakan konsep untuk mengkombinasikan beberapa pohon keputusan sehingga menghasilkan performansi klasifikasi yang lebih baik dibanding hanya menggunakan satu pohon keputusan.

\section{KAJIAN PUSTAKA}

\section{A. Teori Demarkasi Karl Popper}

Menurut Popper [7], bagaimana kriteria untuk membedakan sains dengan pseudo-sains dikenal sebagai masalah demarkasi. Popper mengajukan kriteria demarkasi adalah falsifiability by experience, yang mana sebuah teori dikatakan sains jika dapat diuji dan memiliki kemungkinan untuk dibantah (difalsifikasi) melalui pengalaman atau eksperimen. Eksperimen bertujuan untuk menguatkan teori tersebut, bukan hanya sekedar memverifikasi. Selain itu eksperimen tersebut juga harus dapat disusun ulang sehingga efek yang dihasilkan dapat direproduksi (reproducible).

\section{B. Adiksi Internet dan Media Sosial}

Internet telah menjadi bagian dari kehidupan manusia di dunia sejak dikembangkannya Netscape pada tahun 1990-an [8]. Perkembangan teknologi informasi dan telekomunikasi yang semakin masif telah mempengaruhi berbagai macam aspek kehidupan manusia seperti cara berkomunikasi dan berinteraksi. Manusia berkomunikasi menggunakan teknologi internet dan media sosial untuk berbagai macam tujuan dan kebutuhan, seperti untuk swafoto, perang cyber, belanja online, personalisasi diri, dan budaya berbagi [9]. Internet addiction (kecanduan internet) mulai menjadi perhatian dari banyak kalangan akademik setelah diperkenalkan oleh Kimberly Young pada tahun 1996 [10]. Dalam penelitian tersebut, terdapat lima jenis kecanduan internet, yaitu: Computer addiction, Net compulsion, Cyber-relationship addiction, Cybersexual addiction, dan Information overload.

Pengaksesan internet tidak dapat terlepas dari penggunaan gawai. Berbagai fitur yang ditawarkan pada gawai dapat digunakan sebagai sarana bisnis, penyimpan data, sarana musik dan hiburan, apalagi saat situasi pandemik ini dapat digunakan sebagai sarana pembelajaran jarak jauh (PJJ). Anggraeni [11] mengkaji tentang pengaruh antara pengetahuan mengenai dampak gawai bagi kesehatan terhadap perilaku pengguna. Dengan menerapkan regresi linier sederhana, hasil penelitian menunjukkan bahwa pengetahuan tentang dampak gawai pada kesehatan berpengaruh sebesar 18,9\% terhadap perilaku penggunaan gawai pada siswa. Utami
[12] meneliti tentang pengaruh negatif dari adiksi gawai terhadap kriteria-kriteria akademik remaja. Hasilnya menunjukkan bahwa pengaruh negatif gawai yang paling banyak ditemukan pada remaja adalah memburuknya prestasi akademik. Ramadhan dan Agung [13] mengkaji tentang hubungan antara tingkat kecanduan gawai dengan perilaku serta gangguan terhadap emosi remaja pada rentang usia 11 s.d. 12 tahun. Dengan menggunakan uji bivariat pada metode chi-square didapatkan hasil bahwa gangguan emosi dan perilaku tidak ada hubungannya dengan tingkat pendidikan ayah, ibu, dan jumlah saudara, namun ada hubungannya dengan tingkat kecanduan gawai. Syahyudin [14] meneliti tentang pengaruh gawai terhadap pola komunikasi dan interaksi sosial siswa. Hasilnya menunjukkan bahwa dampak negatif terbesar yang ditimbulkan adalah siswa malas untuk beraktifitas sosial dan kurang mampu berkonsentrasi.

Penelitian [15] tentang adiksi media sosial seperti WhatsApp dan Instagram pada usia remaja menunjukkan bahwa ada dua peran Instagram yang menjadi penyebab utama adiksi yaitu kebutuhan untuk bersosialisasi dan mendapatkan kesenangan, serta ada empat peran WhatsApp yang menjadi penyebab utama adiksi yaitu kebutuhan untuk dapat melakukan banyak hal, bersosialisasi, mendapatkan kesenangan, dan memperoleh rasa aman juga mengendalikan situasi. Sifa dan Sawitri [16] meneliti tentang hubungan antara adiksi media sosial Instagram dengan regulasi diri. Hasilnya menunjukkan adanya hubungan negatif antara tingkat adiksi dengan regulasi diri, dimana semakin tinggi tingkat regulasi diri maka akan semakin rendah potensi adiksi, begitu pun sebaliknya. Soliha [17] menyimpulkan bahwa terdapat hubungan positif sebesar 31,4\% tingkat ketergantungan pengguna media sosial terhadap kecemasan sosial.

\section{Klasifikasi dengan Extreme Gradient Boosting (XGBoost)}

Klasifikasi merupakan proses analisa data untuk menghasilkan model-model classifier yang mampu mengelompokkan data ke dalam kelas-kelas tertentu [18]. Di dalam penelitian ini digunakan algoritma XGBoost untuk melakukan proses klasifikasi menggunakan decision tree. Algoritma XGBoost diperkenalkan oleh Chen dan Guestrin [6], merupakan algoritma klasifikasi yang menggunakan konsep boosting, yaitu proses secara iteratif untuk memperkuat classifier lemah sehingga semakin lama classifier menjadi semakin tinggi performansinya. Algoritma XGBoost menggunakan decision tree untuk menghitung nilai residual yang merupakan selisih antara output dari classifier base model dengan nilai target. Di awal, nilai residual ini akan besar karena classifier belum mempelajari pola dari target Namun seiring dengan bertambahnya iterasi, algoritma $X G B o o s t$ akan menambahkan decision tree sehingga nilai residual semakin mengecil.

Algoritma XGBoost sebagai berikut: 
1. Bangun base model classifier. Base model classifier dapat dibentuk dari beberapa cara, salah satunya menggunakan default value 0,5 untuk kasus biner atau dengan menghitung rata-rata nilai output target.

2. Hitung nilai residual dari masing-masing output target.

3. Dari nilai residual target, lakukan pembangunan decision tree dengan output adalah nilai residual tersebut.

4. Lakukan perhitungan nilai output classifier yang baru dengan menggunakan base model, decision tree dan learning rate.

5. Ulangi proses 2 s.d. 4 hingga konvergen atau hingga mencapai jumlah decision tree yang diinginkan.

Output classifier dari XGBoost dihitung menggunakan Persamaan (1), yang mana $\alpha$ adalah learning rate, $f_{0}(x)$ adalah output dari base model classifier dan $f_{i}(x)$ adalah nilai output dari decision tree. Sedangkan fungsi obyektifnya dihitung dengan Persamaan (2) s.d. Persamaan (5), yang mana $T$ adalah jumlah daun pada decision tree, $Y$ adalah threshold bobot dari daun pada decision tree, $\lambda$ adalah threshold ukuran decision tree, $q\left(x_{i}\right)$ memetakan fitur ke-i dengan daun ke-j pada decision tree, dan $l\left(y_{i} \cdot \hat{y}^{(t-1)}\right)$ adalah loss function.

$$
\begin{aligned}
& \hat{y}_{i}=\phi\left(x_{i}\right)=f_{0}\left(x_{i}\right)+\sum_{k=1}^{K} \alpha f_{k}\left(x_{i}\right) \\
& O b_{j}(F t)=-\frac{1}{2} \sum_{j=1}^{T} \frac{\sigma_{j}^{2}}{H_{j}+\lambda}+\gamma T \\
& G_{j}=\sum_{i \in I_{j}} \partial_{\hat{y}^{(t-1)}} l\left(y_{i} \cdot \hat{y}^{(t-1)}\right) \\
& H_{j}=\sum_{i \in U_{j}} \partial_{\hat{y}(t-1)}^{2} l\left(Y_{i} \cdot \hat{y}^{(t-1)}\right) \\
& I=\left\{i \| q\left(x_{i}\right)=j\right.
\end{aligned}
$$

\section{Metode PENELITIAN}

Tahapan yang dilakukan untuk membuktikan apakah fenomena adiksi internet dan media sosial di Indonesia merupakan saintifik atau bukan, dengan cara mengukur tingkat adiksi internet dan media sosial di Indonesia, menguji pengaruh berbagai variabel yang diduga berpengaruh terhadap adiksi internet dan media sosial, serta menganalisis apakah algoritma XGBoost dapat digunakan untuk membangun model yang dapat mendeteksi adiksi internet dan media sosial di Indonesia. Penelitian dimulai dari penyusunan kuisioner, pra survei untuk uji validitas dan reliabilitas dari kuisioner yang telah dirancang, survei, analisa variabel yang diduga memiliki hubungan dengan adiksi internet dan media sosial, hasil pengujian dengan XGBoost, serta kajian dari sudut pandang filsafat sains.

\section{A. Penyusunan Kuesioner}

Pertanyaan kuisioner disusun berdasarkan penelitian Kimberly Young tentang adiksi internet [19]. Terdapat empat variabel bebas $\mathrm{X}$ dan satu variabel terikat $\mathrm{Y}$ yang tersebar dalam bentuk 20 pertanyaan. Empat variabel bebas $\mathrm{X}$ tersebut yaitu time (X1), relationship (X2), productivity (X3), dan thought (X4). Satu variabel terikat $\mathrm{Y}$ yaitu addiction (Y1). Pada penelitian ini, terdapat 20 pertanyaan untuk mengetahui tingkat adiksi internet dan 20 pertanyaan untuk mengetahui tingkat adiksi media sosial. Setiap pertanyaan memiliki enam pilihan jawaban beserta skor konversinya, yaitu: tidak pernah (0), jarang (1), kadang-kadang (2), sering (3), sangat sering (4), dan selalu (5).

\section{B. Pra Survei}

Pra-survei diperlukan untuk menguji apakah kuisioner yang telah disusun valid dan reliabel untuk dijadikan instrumen dalam penelitian. Pra survei dilaksanakan dari tanggal 27 s.d. 31 Oktober 2020, dan diperoleh sebanyak 200 responden.

\section{Uji Validitas dan Uji Reliabilitas}

Uji validitas bertujuan untuk menilai ketepatan dan kecermatan alat ukur dalam melakukan fungsinya. Secara teknis, uji validitas mengkorelasikan antara masingmasing skor pertanyaan dengan skor total dari jawaban responden atas kuisioner yang diberikan. Pada penelitian ini, uji validitas menggunakan metode Product Moment sesuai dengan Persamaan (6) [20].

$$
r_{x y}=\frac{N \sum x y-\sum x \sum y}{\sqrt{\left(N \sum x^{2}-\left(\sum x\right)^{2}\right)\left(N \sum y^{2}-\left(\sum y\right)^{2}\right)}}
$$

dimana $r_{x y}$ merupakan koefisien korelasi antara variabel $x$ dan variable $y, N$ merupakan jumlah data. Teknik dari Product Moment yaitu membandingkan nilai Sig. (2-tiled) dengan probabilitas 0,05 . Item pertanyaan kuisioner valid jika nilai Sig. (2-tiled) < 0,05 dan Pearson Correlation bernilai positif, selain itu maka item pertanyaan kuisioner tidak valid. Hasil uji validitas menunjukkan bahwa semua butir pertanyaan dalam kuisioner ini bersifat valid.

Sedangkan uji reliabilitas bertujuan untuk menilai tingkat konsistensi kuisioner agar handal dalam mengukur variabel penelitian, walaupun penelitian ini dilakukan berulang-ulang dengan menggunakan kuisioner yang sama. Uji reliabilitas menggunakan metode Alpha Cronbach's sesuai dengan Persamaan (7) [20].

$$
r_{11}=\left(\frac{n}{n-1}\right)\left(1-\frac{\sum \sigma_{t}^{2}}{\sigma_{t}}\right)
$$

dimana $r_{11}$ merupakan nilai reliabilitas yang dicari, $n$ merupakan jumlah item pertanyaan yang diuji, dan $\sigma_{t}$ merupakan nilai variansi setiap item pertanyaan.

TABEL I

HASIL UJI RELIABILITAS

\begin{tabular}{|l|c|c|c|c|}
\hline \multirow{2}{*}{ Variabel } & \multicolumn{2}{|c|}{ Adiksi Internet } & \multicolumn{2}{c|}{ Adiksi Media Sosial } \\
\cline { 2 - 5 } & Sedang & Tinggi & Sedang & Tinggi \\
\hline Time & & $\checkmark$ & & $\checkmark$ \\
\hline Relationship & $\checkmark$ & & $\checkmark$ & \\
\hline Productivity & & $\checkmark$ & & $\checkmark$ \\
\hline Thought & & $\checkmark$ & & $\checkmark$ \\
\hline Addiction & & $\checkmark$ & & $\checkmark$ \\
\hline
\end{tabular}

Tabel I merupakan hasil uji reabilitas dari penelitian ini. Mayoritas semua variabel dengan kategori tinggi. 
Berdasarkan hasil yang diperoleh pada Tabel I menunjukkan bahwa kuisioner yang telah disusun bersifat sangat reliabel.

\section{Survei dan Pengolahan Awal}

Survei dilaksanakan pada tanggal 1 s.d. 4 November 2020, dan menghasilkan 2309 data mentah. Selanjutnya dilakukan pengolahan awal berupa cleaning data untuk menghapus data yang duplikat, dan missing value yaitu pada atribut usia pertama kali memiliki gawai, usia pertama kali mengakses internet, dan usia pertama kali memiliki akun media sosial. Sehingga tersisa 1980 data yang akan diolah pada tahap selanjutnya.

\section{E. Klasifikasi Tingkat Adiksi Internet dan Media Sosial}

Pada tahap ini dilakukan pengolahan data survei adiksi internet untuk mengetahui tingkat adiksi internet pada responden dengan cara mengkonversikan setiap jawaban survei ke dalam skor numerik dalam rentang 0 s.d. 5, menjumlahkannya menjadi satu nilai skor total dalam rentang 0 s.d. 100, kemudian mengidentifikasi tingkat adiksi internet berdasarkan skor total sesuai ketentuan internet addiction test (IAT) [19], yaitu normal (0 - 30), mild (31 - 49), moderate (50 - 79) dan severe (80 - 100). Proses yang sama juga dilakukan untuk mengidentifikasi tingkat adiksi media sosial dengan menggunakan data survei adiksi media sosial.

\section{HASIL DAN PEMBAHASAN}

Bab ini memaparkan hasil penelitian yang diperoleh, yaitu: hasil survei, uji hipotesis dengan chi-square, pembangunan model klasifikasi adiksi menggunakan algoritma XGBoost, serta kajian adiksi internet dan media sosial berdasarkan sudut pandang filsafat sains.

\section{A. Hasil Survei}

Gambar. 1 merupakan hasil identifikasi yang diperoleh melalui survei. Dari 1980 responden didapatkan hasil sebagai berikut: $25,55 \%$ responden teradiksi internet (mild $20.25 \%$, moderate $4,85 \%$, severe $0,45 \%$ ) dan $20,2 \%$ teradiksi media sosial (mild $15 \%$, moderate $4,75 \%$, severe $0,45 \%)$. Hal ini membuktikan bahwa adiksi internet dan media sosial di Indonesia adalah nyata.

\section{B. Uji Hipotesis}

Hipotesis utama dari penelitian ini adalah fenomena adiksi internet dan media sosial di Indonesia adalah nyata dan merupakan sains. Untuk mendukung hipotesis tersebut, dilakukan pengujian terhadap variabel yang diduga dapat mempengaruhi adiksi internet dan media sosial dengan menggunakan uji chi-square. Berikut adalah variabel-variabel yang dimaksud beserta kemungkinan nilainya.

Variabel bebas $(\mathrm{X})$ yaitu:

- Jenis kelamin: laki-laki, perempuan
- Kelompok usia: kanak-kanak (7 - 11 tahun), remaja awal (12 - 16 tahun), remaja akhir (17 - 25 tahun), dewasa awal (26 - 35 tahun), dewasa akhir (36 - 45 tahun), lansia awal (46 - 55 tahun), lansia akhir (56 - 65 tahun), manula (> 65 tahun) [21]

- Pendidikan: SD, SMP, SMA, D3, D4, S1, S2, S3

- Pekerjaan: pelajar/ mahasiswa, pekerja, tidak bekerja

- Domisili: Kepulauan Nusa Tenggara, Jawa, Sumatra, Sulawesi, Kalimantan, Papua, Luar negeri

- Usia pertama kali memiliki gawai: < 10 tahun, 10 20 tahun, 20 - 30 tahun, 30 - 40 tahun, 40 - 50 tahun, > 50 tahun

- Usia pertama kali mengakses internet: < 10 tahun, 10 - 20 tahun, 20 - 30 tahun, 30 - 40 tahun, 40 - 50 tahun, dan > 50 tahun

- Usia pertama kali memiliki akun media sosial: < 10 tahun, 10 - 20 tahun, 20 - 30 tahun, 30 - 40 tahun, 40 - 50 tahun, dan $>50$ tahun

- Durasi akses situs non media sosial: $<3$ jam, 3 - 5 jam, 6 - 11 jam, dan $>11$ jam

- Durasi akses media sosial: < 3 jam, 3 - 5 jam, 6 - 8 jam, dan $>8$ jam

Variabel terikat (Y) yaitu:

- Tingkat adiksi internet: Normal, Mild, Moderate, Severe

- Tingkat adiksi media sosial: Normal, Mild, Moderate, Severe

Adapun parameter yang digunakan adalah Significance value $=0,05$ dan Degree of freedom (df) sesuai Persamaan 8 [22].

$$
d f=(m-1)(n-1)
$$

dimana $m$ adalah banyaknya kemungkinan nilai $\mathrm{X}$ dan $n$ adalah banyaknya kemungkinan nilai $Y$. Tabel II merupakan hasil uji square terhadap variabel-variabel bebas.

Berdasarkan hasil uji chi-square pada Tabel II, diperoleh bahwa faktor-faktor yang mempengaruhi adiksi internet adalah kelompok usia, pendidikan, pekerjaan, usia pertama kali memiliki gawai sendiri, usia pertama kali mengakses internet, usia pertama kali memiliki akun media sosial, durasi akses situs non media sosial, dan durasi akses media sosial. Sedangkan faktor-faktor yang mempengaruhi adiksi media sosial adalah kelompok usia, pekerjaan, usia pertama kali memiliki gawai, usia pertama kali mengakses internet, usia pertama kali memiliki akun media sosial, durasi akses situs non media sosial, dan durasi akses media sosial. Selanjutnya dilakukan analisis lebih lanjut untuk melihat peluang adiksi internet dan media sosial pada setiap variabel yang terbukti berpengaruh $P(Y \mid X)$. Untuk memudahkan analisis, peluang tersebut divisualisasikan dalam bentuk grafik yang dapat dilihat pada Gambar. 2 s.d. Gambar. 9. 

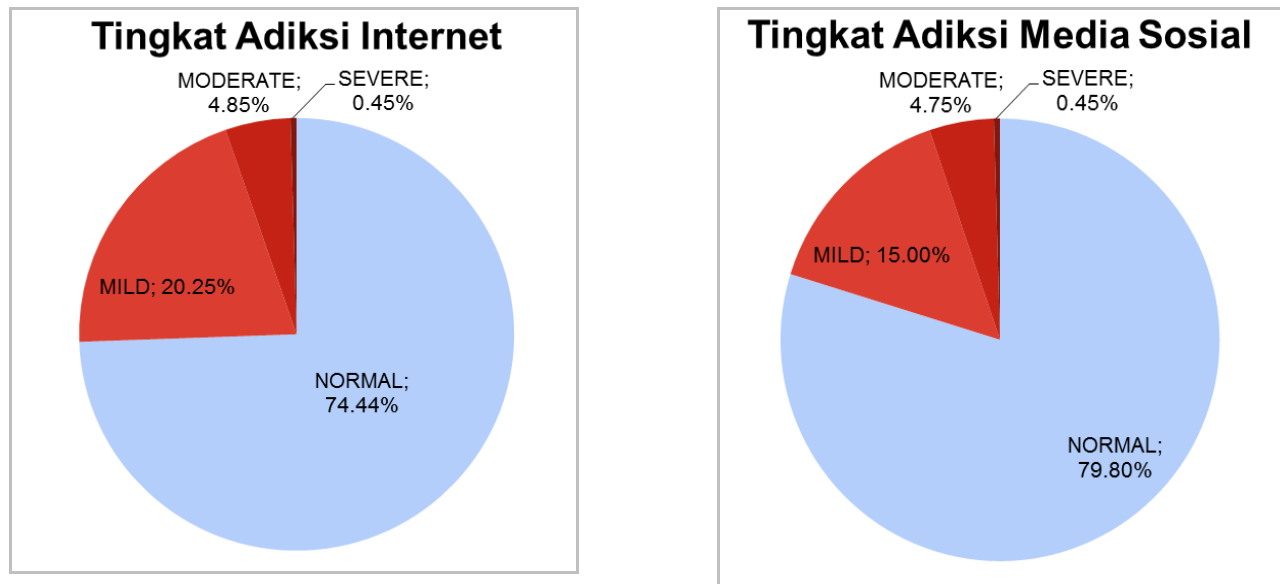

Gambar. 1 Hasil identifikasi tingkat adiksi internet dan media sosial pada responden

TABEL III

HASIL UJi CHI-SQUARE

\begin{tabular}{|c|l|c|c|c|c|c|c|c|c|}
\hline \multirow{2}{*}{ No } & \multicolumn{1}{|c|}{ Variabel } & \multicolumn{4}{|c|}{ Adiksi Internet } & \multicolumn{4}{c|}{ Adiksi Media Sosial } \\
\cline { 3 - 10 } & df & Chi hitung & Chi tabel & Pengaruh & df & Chi hitung & Chi tabel & Pengaruh \\
\hline 1 & Jenis Kelamin & 3 & 2,53 & 7,82 & Tidak & 3 & 4,77 & 7,82 & Tidak \\
\hline 2 & Kelompok Usia & 21 & 138,8 & 32,67 & Ya & 21 & 102,50 & 32,67 & Ya \\
\hline 3 & Pendidikan & 21 & 48,20 & 32,71 & Ya & 21 & 24,25 & 32,67 & Tidak \\
\hline 4 & Pekerjaan & 6 & 50,35 & 12,59 & Ya & 6 & 39,54 & 12,59 & Ya \\
\hline 5 & Domisili & 18 & 6,36 & 28,86 & Tidak & 18 & 8,00 & 28,87 & Tidak \\
\hline 6 & $\begin{array}{l}\text { Usia pertama kali } \\
\text { memiliki gawai }\end{array}$ & 15 & 106,53 & 24,96 & Ya & 15 & 48,88 & 24,96 & Ya \\
\hline 7 & $\begin{array}{l}\text { Usia pertama kali } \\
\text { mengakses internet }\end{array}$ & 15 & 106,5 & 24,99 & Ya & 15 & 48,88 & 24,99 & Ya \\
\hline 8 & $\begin{array}{l}\text { Usia pertama kali } \\
\text { memiliki akun } \\
\text { media sosial }\end{array}$ & 15 & 131,86 & 24,99 & Ya & 15 & 70,40 & 24,99 & Ya \\
\hline 9 & $\begin{array}{l}\text { Durasi akses situs } \\
\text { non media sosial }\end{array}$ & 9 & 56,46 & 16,92 & Ya & 9 & 51,72 & 169,9 & Ya \\
\hline 10 & $\begin{array}{l}\text { Durasi akses media } \\
\text { sosial }\end{array}$ & 168,55 & 16,92 & Ya & 9 & 87,6 & 16,92 & Ya \\
\hline
\end{tabular}
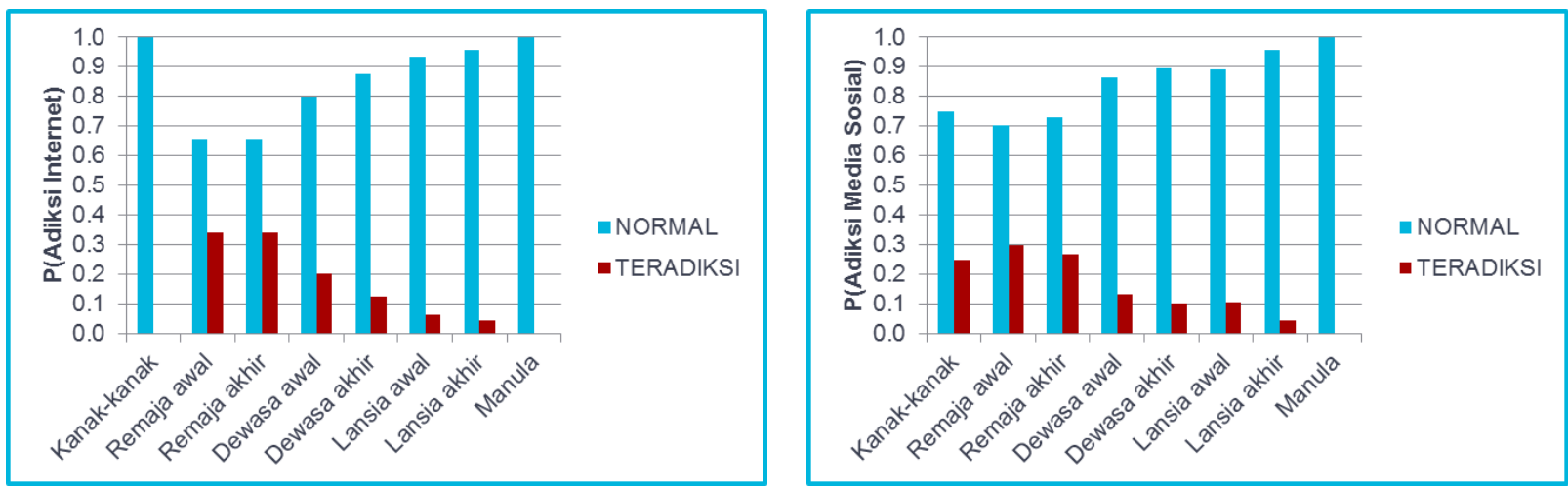

Gambar. 2 Peluang adiksi internet dan media sosial berdasarkan kelompok usia 

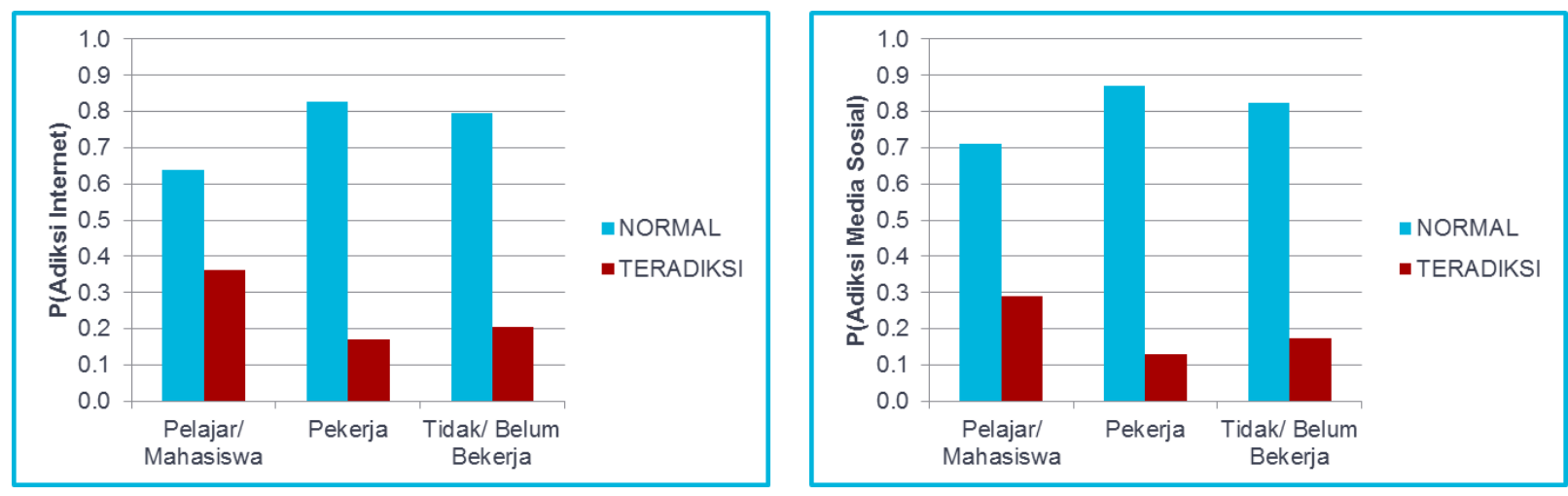

Gambar. 3 Peluang adiksi internet dan media sosial berdasarkan pekerjaan

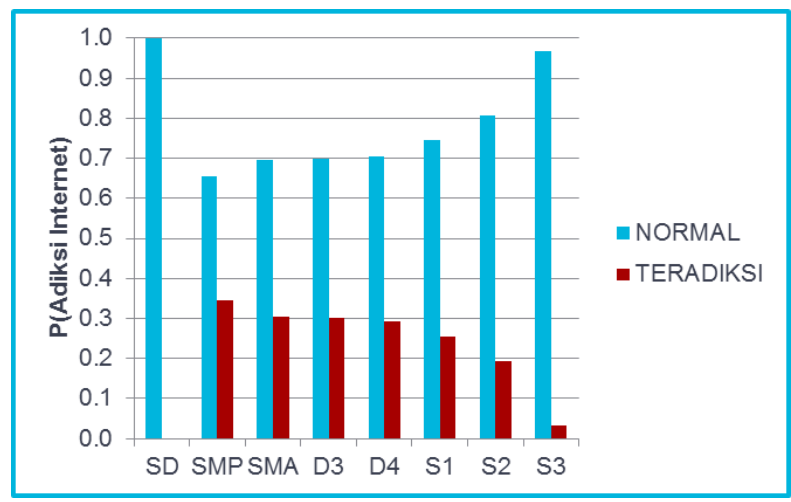

Gambar. 4 Peluang adiksi internet berdasarkan tingkat pendidikan
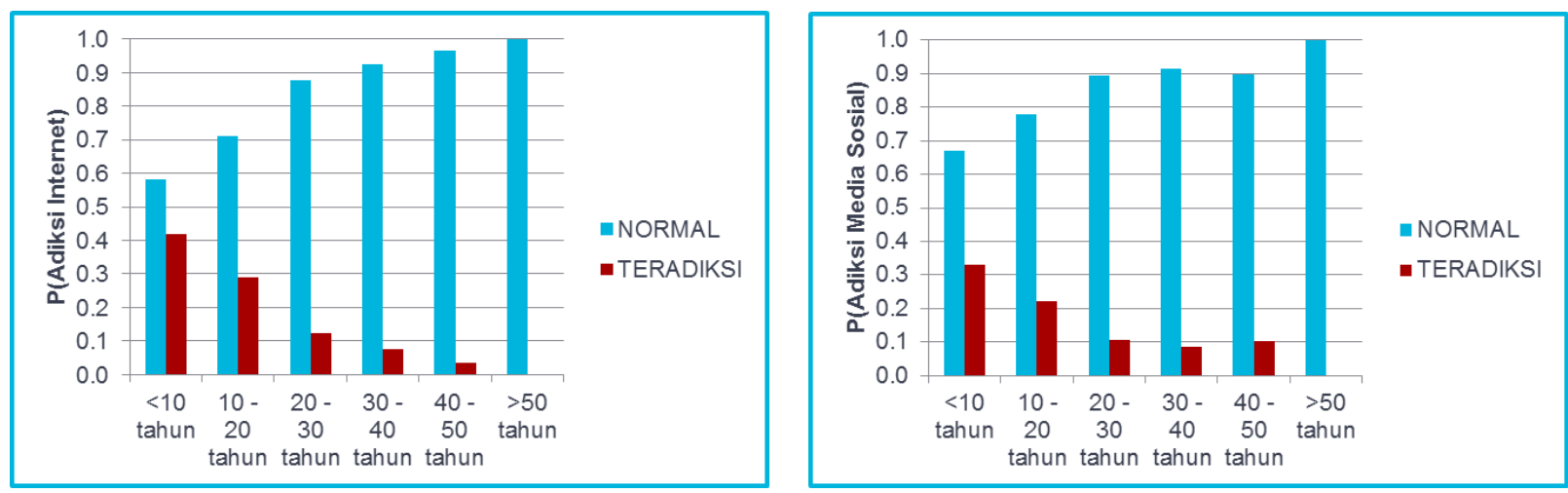

Gambar. 5 Peluang adiksi internet dan media sosial berdasarkan usia pertama kali memiliki gawai
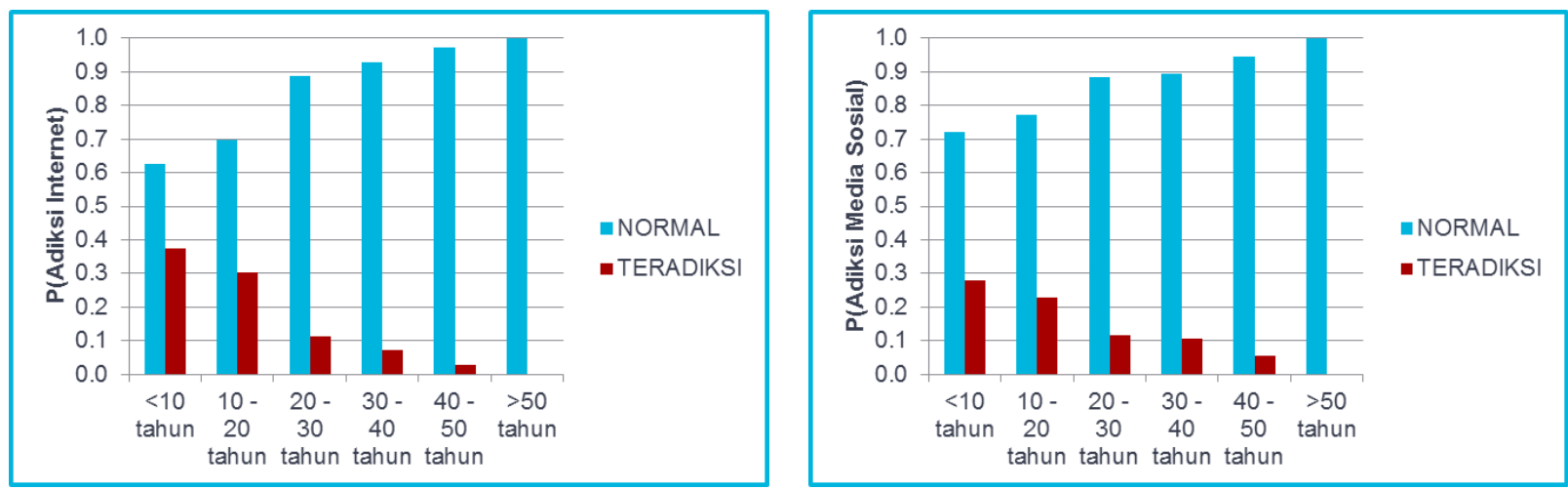

Gambar. 6 Peluang peluang adiksi internet dan media sosial berdasarkan usia pertama kali mengakses internet 

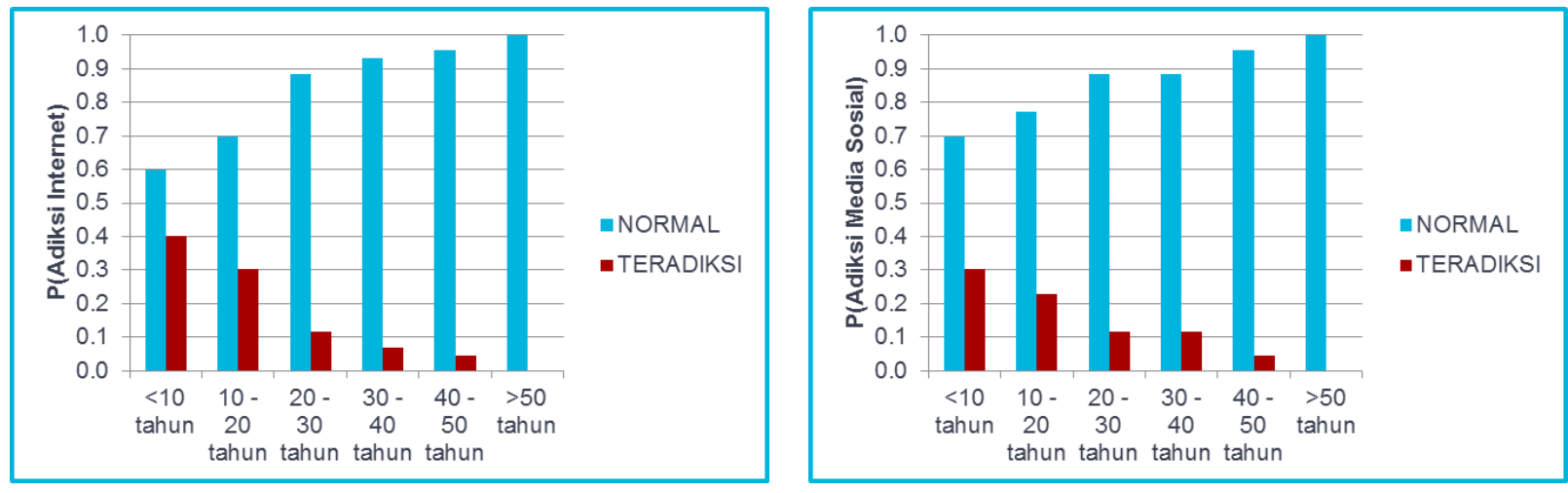

Gambar. 7 Peluang adiksi internet dan media sosial berdasarkan usia pertama kali memiliki akun media sosial
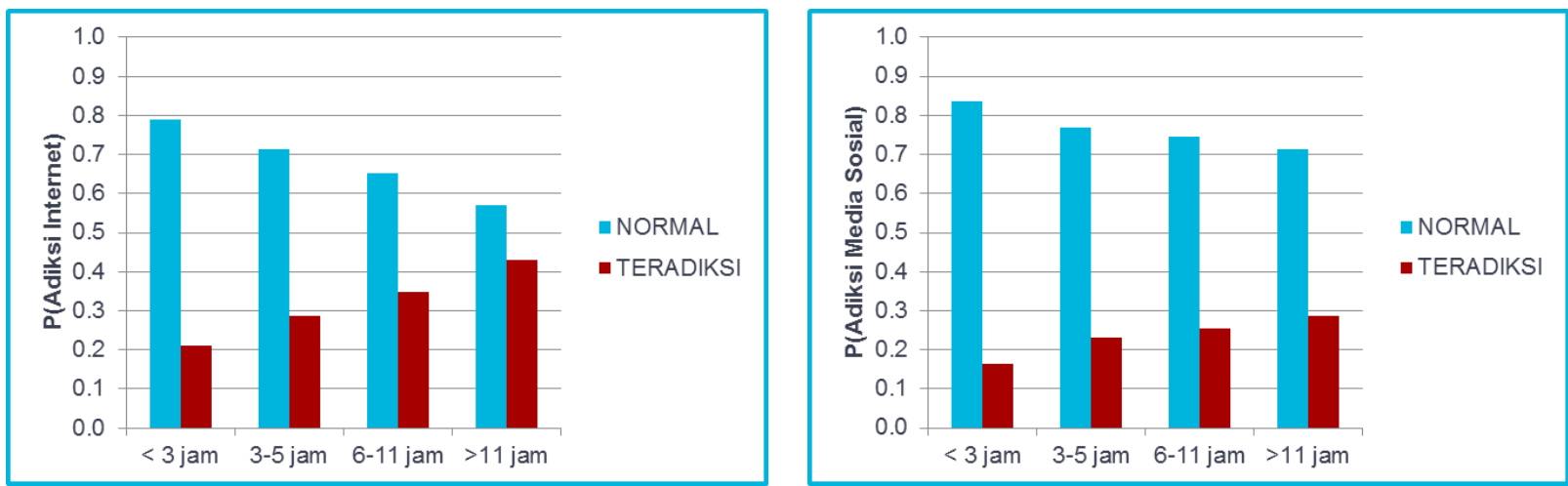

Gambar. 8 Peluang adiksi internet dan media sosial berdasarkan durasi akses situs non media sosial
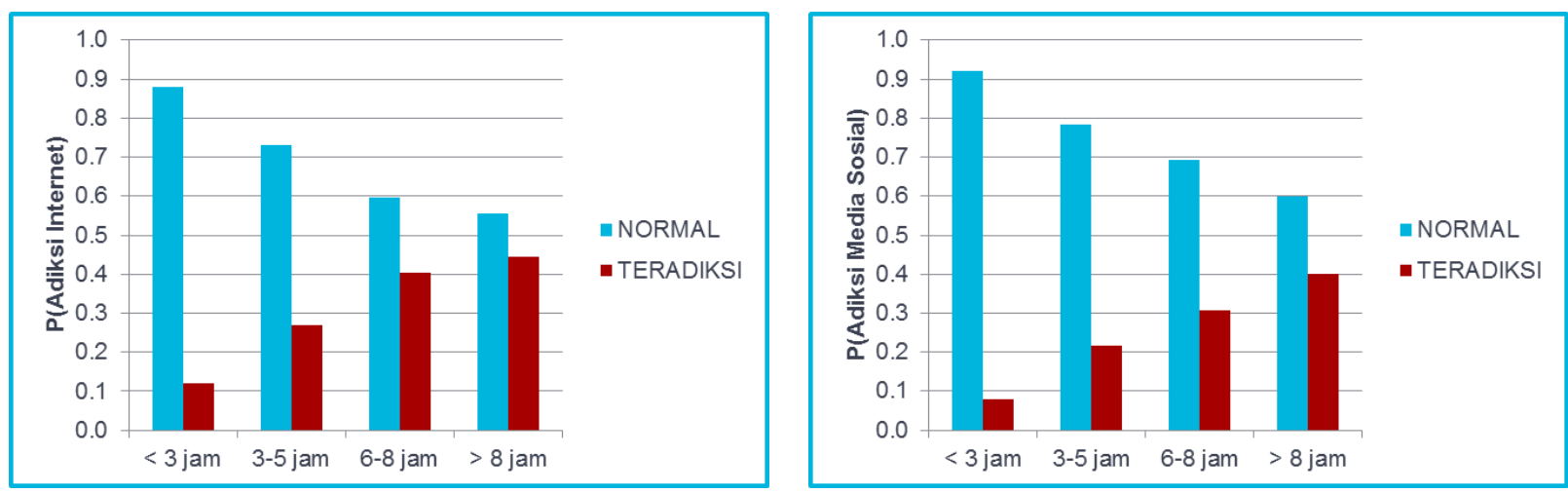

Gambar. 9 Peluang adiksi internet dan media sosial berdasarkan durasi akses media sosial

Hasil analisis Gambar. 2 s.d. Gambar. 9 sebagai berikut:

- Remaja awal dan remaja akhir merupakan kelompok usia yang berpeluang paling tinggi untuk teradiksi internet dan media sosial dibanding kelompok usia lain, yang mana kelompok usia tersebut umumnya merupakan pelajar/ mahasiswa SMP s.d. perguruan tinggi S1 (Gambar. 2 s.d. 4).

- Semakin dini seseorang mengenal gawai, internet, dan media sosial, maka semakin tinggi peluangnya untuk teradiksi internet dan media sosial (Gambar. 5 s.d. 7).

- Berdasarkan Gambar. 8 s.d. 9, mengakses internet dalam durasi yang lama (lebih dari 8 jam per hari untuk akses media sosial dan lebih dari 11 jam per hari untuk akses situs non media sosial) dapat meningkatkan peluang untuk teradiksi internet dan media sosial.

Berdasarkan hasil analisis di atas, maka saran untuk mencegah seseorang teradiksi internet dan media sosial adalah sebagai berikut:

- Tunda penggunaan gawai, internet, dan media sosial kepada seseorang setelah berusia matang. Penggunaan sebelum usia tersebut harus ada persetujuan dan pengawasan dari orang tua. Hal ini sesuai dengan usulan dari Kementerian Komunikasi dan Informatika (Kominfo) yang akan dimuat 
dalam Rancangan Undang-Undang Perlindungan Data Pribadi (RUU PDP).

- Batasi dan kendalikan durasi penggunaan internet dan media sosial, kecuali untuk kegiatan produktif.

- Selektif dalam mengakses dan memiliki akun media sosial.

\section{Hasil Klasifikasi dengan XGBoost}

Dari hasil uji variabel dengan chi-square didapatkan variabel-variabel yang berpengaruh terhadap adiksi internet dan media sosial. Selanjutnya variabel-variabel tersebut dimodelkan dalam bentuk decision tree menggunakan algoritma XGBoost agar dapat digunakan untuk mendeteksi apakah seseorang teradiksi internet dan media sosial atau tidak. Dataset yang digunakan terdiri dari 1980 data. Tabel III merupakan rincian dari data yang digunakan.

Jumlah data antara kedua kelas tidak seimbang (imbalance) dengan rasio 1:3 untuk adiksi internet dan 1:4 untuk adiksi media sosial. Sehingga untuk mengatasi hal tersebut, dilakukan proses random undersampling dan oversampling [23]. Kemudian dilakukan proses pelatihan algoritma XGBoost dengan skema 5-fold cross validation menggunakan hyperparameter default dari XGBoost XGBClassifier pada Phyton. Gambar. 10 dan Gambar. 11 merupakan contoh decision tree yang dihasilkan dari algoritma XGBoost untuk mendeteksi adiksi internet dan media sosial. Nilai pada leaf menunjukkan nilai output dari masing-masing leaf.

TABEL III RINCIAN DATASET

\begin{tabular}{|l|c|c|}
\hline \multicolumn{1}{|c|}{ Kelas } & Adiksi Internet & $\begin{array}{c}\text { Adiksi Media } \\
\text { Sosial }\end{array}$ \\
\hline Teradiksi (1) & 506 & 400 \\
\hline Normal (0) & 1474 & 1580 \\
\hline
\end{tabular}

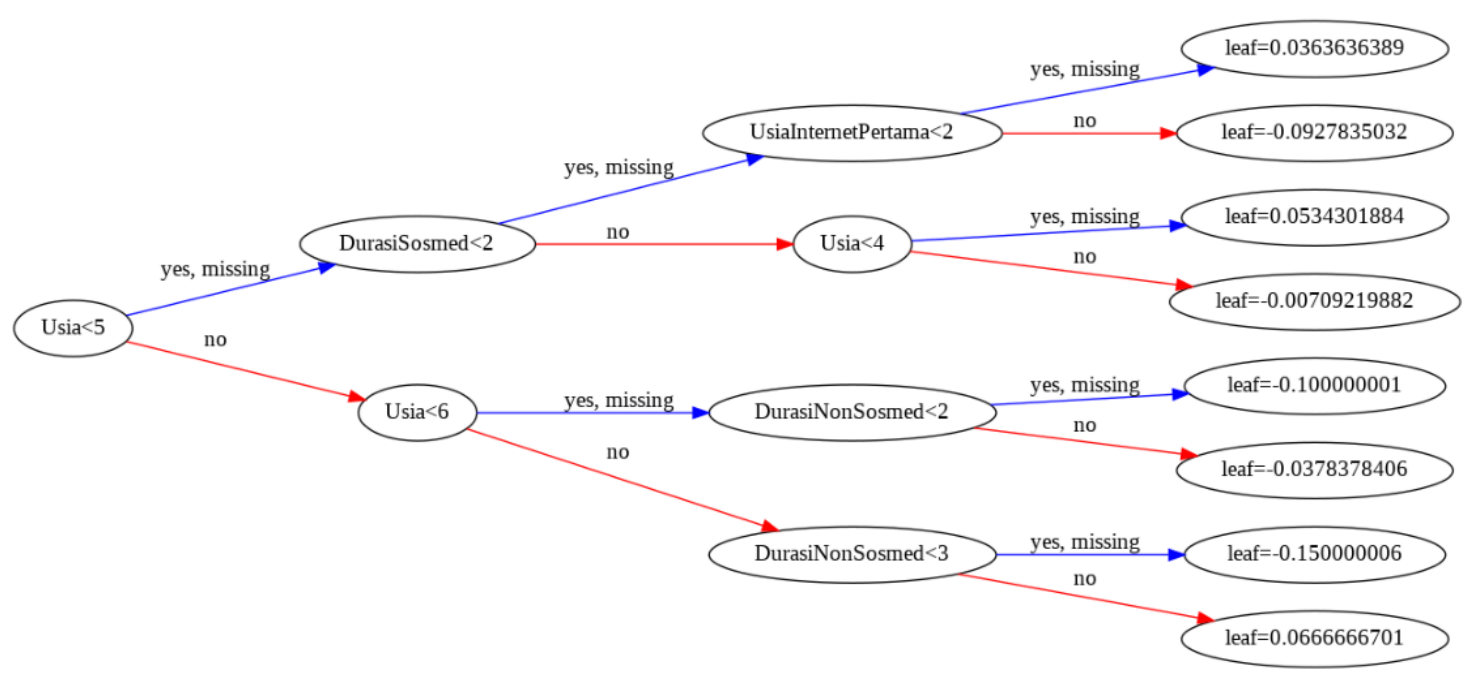

Gambar. 10 Contoh Decision Tree dari XGBoost untuk deteksi adiksi internet

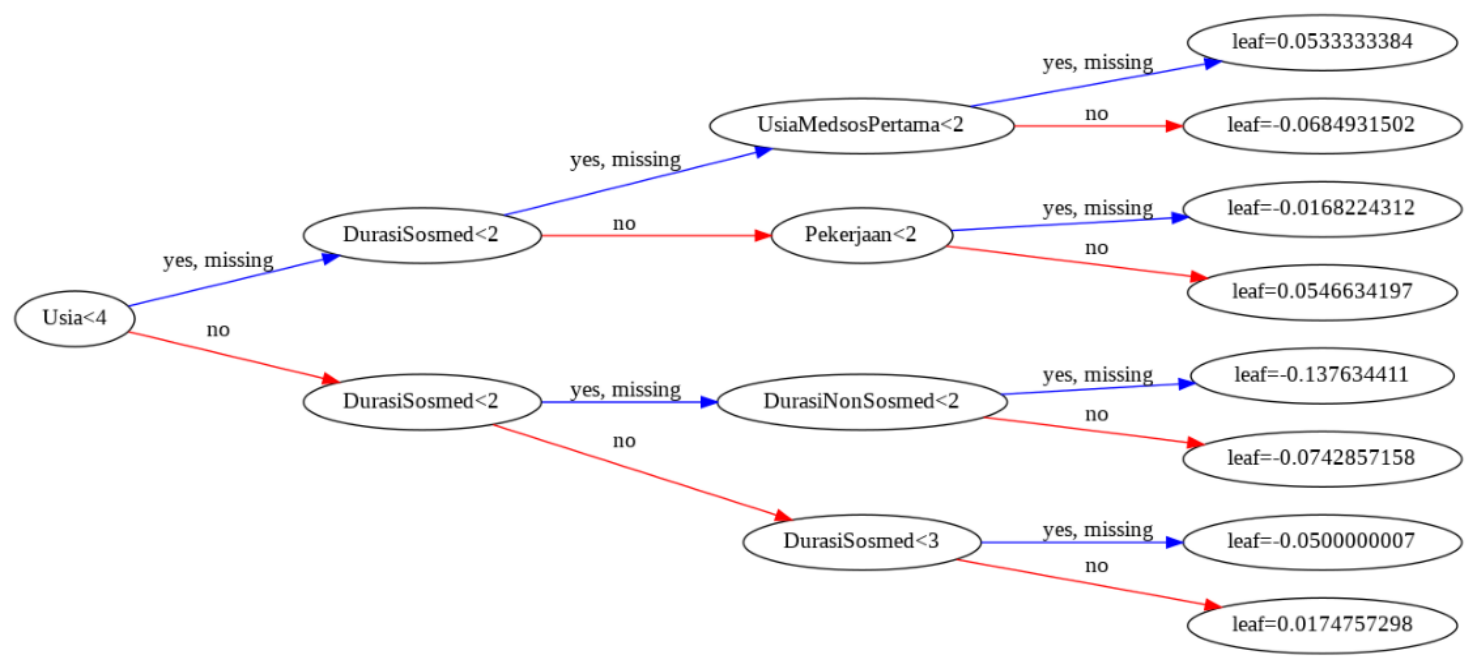

Gambar. 11 Contoh Decision Tree dari XGBoost untuk deteksi adiksi medsos 
Berdasarkan hasil pengujian didapatkan nilai performansi rata-rata untuk 5-fold, seperti yang dapat dilihat pada Tabel IV. Saat imbalance class tidak ditangani, sistem kurang mampu untuk mendeteksi adiksi dan cenderung untuk mengklasifikasikan data sebagai kelas normal. Hal ini terlihat dari nilai accuracy yang tinggi namun F-Measure yang sangat rendah. Performansi terbaik didapatkan saat dilakukan penanganan imbalance class dengan oversampling. Walaupun hasilnya belum optimal, namun penanganan ini mampu meningkatkan performansi sistem dari sisi F-Measure secara signifikan. Hal menunjukkan bahwa dengan penanganan imbalance class, sistem menjadi lebih baik dalam mendeteksi adiksi.

TABEL IV

PERFORMANSI MODEL KLASIFIKASI XGBOOST

\begin{tabular}{|l|r|r|r|r|r|r|r|c|}
\hline \multirow{2}{*}{ Skenario } & \multicolumn{4}{|c|}{ Adiksi Internet } & \multicolumn{4}{c|}{ Adiksi Media Sosial } \\
\cline { 2 - 9 } & Accuracy & Precision & Recall & F-Measure & Accuracy & Precision & \multicolumn{1}{c|}{ Recall } & F-Measure \\
\hline Imbalance Class & $73,38 \%$ & $44,90 \%$ & $8,18 \%$ & $13,41 \%$ & $79,95 \%$ & $65,24 \%$ & $2,57 \%$ & $4,89 \%$ \\
\hline Undersampling & $61,07 \%$ & $59,08 \%$ & $70,12 \%$ & $64,04 \%$ & $63,25 \%$ & $61,79 \%$ & $69,77 \%$ & $65,49 \%$ \\
\hline Oversampling & $66,39 \%$ & $63,84 \%$ & $75,72 \%$ & $\mathbf{6 9 , 2 3 \%}$ & $65,09 \%$ & $63,09 \%$ & $73,07 \%$ & $\mathbf{6 7 , 6 6 \%}$ \\
\hline
\end{tabular}

Model XGBoost yang telah dibangun juga dapat diekstraksi feature importance, yaitu jumlah kemunculan fitur di seluruh decision tree pada model XGBoost classifier. Gambar. 12 adalah feature importance dari model klasifikasi XGBoost untuk adiksi internet dan media sosial. Dari gambar tersebut terlihat bahwa tiga variabel yang paling berpengaruh dalam model klasifikasi
XGBoost untuk mendeteksi adiksi internet adalah pendidikan, durasi akses media sosial, dan usia pertama kali memiliki akun media sosial. Sedangkan variabel untuk mendeteksi adiksi media sosial adalah durasi akses media sosial, durasi akses situs non media sosial, dan kelompok usia.
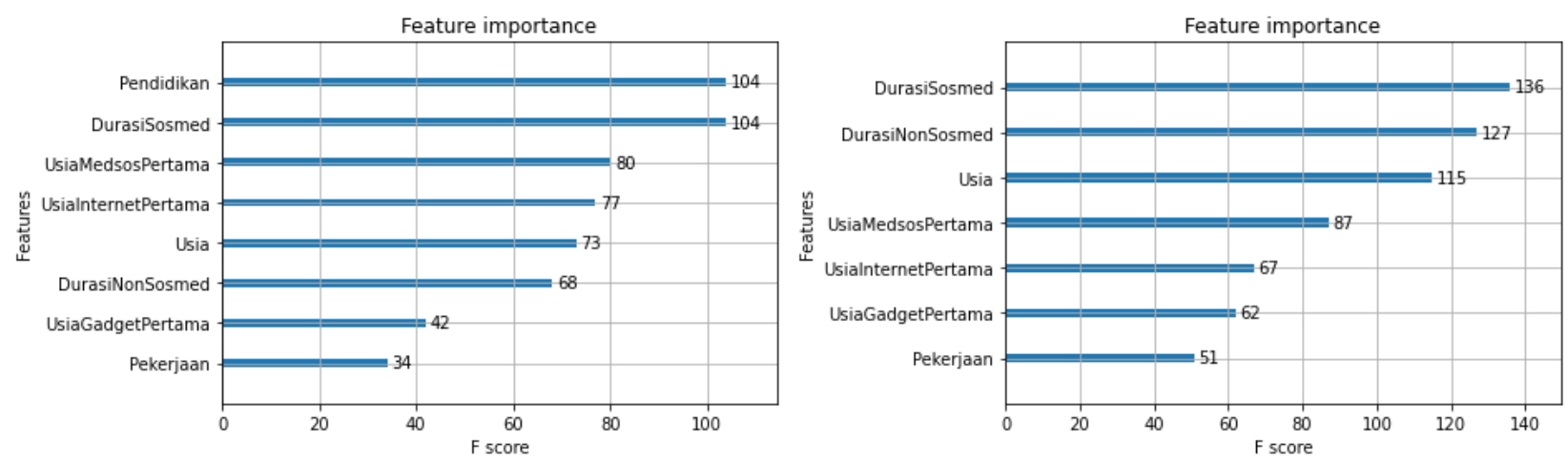

Gambar. 12 Feature Importance model klasifikasi adiksi internet (kiri) dan media sosial (kanan)

\section{Proyeksi Adiksi Internet dan Media Sosial di Indonesia}

Dari hasil survei terhadap 1980 responden, diketahui sebanyak $25,55 \%$ teradiksi internet dan $31,88 \%$ teradiksi media sosial. Selanjutnya akan diestimasi banyaknya pengguna internet dan media sosial di Indonesia yang teradiksi pada tahun 2020, dan proyeksi untuk tahun 2021. Untuk menyederhanakan estimasi, peluang teradiksi diasumsikan mengikuti distribusi binomial. Pertama, hitung binomial confidence interval menggunakan normal approximation interval. Pada metode ini, confidence interval $(C I)$ untuk proporsi populasi dihitung dengan menggunakan Persamaan (9) dan (10) [24].

$$
\begin{aligned}
& \text { error_bound }=z^{*} \sqrt{\frac{(1-p)}{n}} \\
& C I=p \pm \text { error_bound }
\end{aligned}
$$

dimana $p$ adalah estimasi proporsi teradiksi pada sampel (responden), $z^{*}$ adalah nilai yang sesuai dari distribusi normal standar untuk tingkat kepercayaan yang diinginkan, dan $n$ adalah jumlah sampel. Pada confidence level $95 \%$, didapatkan error bound $1,92 \%$ untuk teradiksi internet dan $1,77 \%$ untuk teradiksi media sosial. Sehingga dapat diinterpretasikan bahwa sebanyak $23,63 \%$ s.d. $27,47 \%$ pengguna internet di Indonesia teradiksi dan $18,43 \%$ s.d. $21,97 \%$ pengguna media sosial di Indonesia teradiksi. Pengguna internet di Indonesia pada tahun 2020 adalah 196.71 juta [3] dan pengguna media sosial aktif adalah 160 juta [25], maka estimasi pengguna internet di Indonesia yang teradiksi pada tahun 2020 adalah sebanyak 46,35 juta s.d. 53,89 juta pengguna, sedangkan untuk pengguna media sosial diperkirakan sebanyak 29,49 juta s.d. 35,15 juta pengguna mengalami adiksi.

Selanjutnya, untuk menghitung proyeksi pengguna yang teradiksi internet dan media sosial pada tahun 2021 
digunakan metode aritmatik sesuai dengan Persamaan (11)

[26].

$$
P_{t}=P_{0}(1+r t)
$$

dimana $P_{t}$ adalah proyeksi pengguna yang teradiksi internet pada tahun $\mathrm{t}, P_{0}$ adalah jumlah pengguna yang teradiksi internet dan media sosial pada tahun dasar, $r$ adalah laju pertambahan pengguna internet, dan $t$ adalah selisih antara tahun dasar dan tahun $\mathrm{t}$ (dalam tahun). Dengan pertumbuhan pengguna internet dan media sosial pada tahun 2020 adalah 8,9\% [3] dan 3\% [25], maka proyeksi pengguna internet di Indonesia yang teradiksi pada tahun 2021 adalah sebanyak 50,48 juta s.d. 58,69 juta pengguna, sedangkan untuk pengguna media sosial diperkirakan sebanyak 30,38 juta s.d. 36,2 juta pengguna mengalami adiksi. Hasil ini menunjukkan bahwa adiksi internet dan media sosial di Indonesia adalah kenyataan saintifik.

\section{E. Kajian Filsafat Sains terhadap Adiksi Internet dan Media Sosial}

Pernyataan dan teori yang diperoleh melalui pengujian empiris pada akhirnya harus disimpulkan. Jika pernyataan itu bertahan dari upaya-upaya menyalahkannya (falsifikasi), maka pernyataan itu dapat dianggap kuat (corborate). Fenomena adiksi internet dan media sosial di Indonesia dikatakan sains karena aspek-aspek sebagai berikut:

- Instrumen penelitian menggunakan kuisioner yang bersumber dari penelitian Kimberly Young [19] yang telah teruji secara empiris dan berhasil direproduksi pada sejumlah penelitian lain seperti [20], [27].

- Dilakukan uji validitas dan uji reliabilitas pada tahap pra survei.

- Dilakukan uji chi-square untuk mengetahui variable-variabel yang berpengaruh terhadap adiksi internet dan media sosial.

- Survei terhadap sejumlah 1980 responden menunjukan bahwa adiksi internet di Indonesia itu nyata, yang mana diperoleh hasil sebanyak 25,56\% responden teradiksi internet (mild 20,25\%, moderate $4,85 \%$, dan severe $0,45 \%$ ) dan $20,2 \%$ teradiksi media sosial (mild 15\%, moderate 4,75\%, severe $0,45 \%)$.

Dengan kata lain, fenomena adiksi internet dan media sosial di Indonesia adalah nyata dan merupakan sains karena dapat diuji (testable) secara empiris, dapat difalsifikasi (falsifiable), dan reproducible.

\section{KESIMPULAN}

Adiksi internet dan media sosial di Indonesia adalah nyata dan merupakan sains karena dapat diuji (testable) secara empiris, dapat difalsifikasi (falsifiable), dan reproducible. Adapun faktanya mengacu pada hasil penelitian bahwa:

1. Dari 1980 responden terbukti sebanyak $25,55 \%$ responden teradiksi internet, dengan rincian: mild
$20,25 \%$, moderate $4,85 \%$, dan severe $0,45 \%$. Sedangkan untuk adiksi media sosial, 20,2\% responden mengalami adiksi dengan rincian: mild $15 \%$, moderate $4,75 \%$, severe $0,45 \%$.

2. Peluang adiksi terbesar terjadi pada kelompok usia remaja awal dan remaja akhir yang umumnya merupakan pelajar/ mahasiswa pada jenjang pendidikan SMP s.d. S1.

3. Faktor yang dapat meningkatkan potensi adiksi internet dan media sosial adalah:

a. Usia terlalu dini ketika mengenal dan menggunakan gawai, internet, dan media sosial.

b. Durasi akses internet dan media sosial yang tidak terkendali untuk hal yang tidak produktif.

4. Algoritma XGBoost berhasil membangun model klasifikasi untuk mendeteksi adiksi internet dan media sosial di Indonesia dengan nilai performansi F-Measure sebesar $69,23 \%$ untuk adiksi internet dan $67,66 \%$ untuk adiksi media sosial.

5. Dengan confidence level $95 \%$, diperkirakan pada tahun 2020 terdapat 46,35 juta s.d. 53.89 juta pengguna internet di Indonesia yang teradiksi, sedangkan untuk pengguna media sosial diperkirakan sebanyak 29,49 juta s.d. 35,15 juta pengguna mengalami adiksi. Untuk proyeksi pada tahun 2021, 50,48 juta s.d. 58,69 juta pengguna internet dan 30,38 juta s.d. 36,2 juta pengguna media sosial di Indonesia diperkirakan terkena adiksi.

Saran untuk pengembangan penelitian selanjutnya yaitu menambah jumlah dan menentukan target profil responden yang ingin dicapai agar sebarannya lebih merata, melakukan pemodelan klasifikasi dengan menggunakan algoritma machine learning lainnya, dan menggunakan metode lain untuk mengestimasi banyaknya pengguna internet dan media sosial yang teradiksi agar didapat hasil estimasi yang lebih detail sesuai tingkat adiksi.

\section{REFERENSI}

[1] E. A. Sosiawan, "Penggunaan Situs Jejaring Sosial sebagai Media Interaksi dan Komunikasi di Kalangan Mahasiswa," J. Ilmu Komun., vol. 9, no. 1, pp. 60-75, 2020.

[2] N. R. Moşteanu, "Using Internet and Edutech Become A Primary Need Rather Than A Luxury - The Reality: A New Skilled Educational System - Digital University Campus," Int. J. Eng. Sci. Technol., vol. 4, no. 6, pp. 1-9, 2020.

[3] APJII, "Laporan Survei Internet APJII 2019 - 2020 (Q2)," 2020

[4] P. Chebbi, K. S. Koong, L. Liu, and R. Rottman, "Some Observations on Internet Addiction Disorder Research," J. Inf. Syst. Educ., vol. 11, no. 3, p. 3, 2020.

[5] Suyanto, Machine Learning Tingkat Dasar dan Lanjut. Bandung: Informatika, 2018.

[6] T. Chen and C. Guestrin, "Xgboost: A scalable tree boosting system," in Proceedings of the 22nd acm sigkdd international conference on knowledge discovery and data mining, 2016, pp. 785-794.

[7] K. Popper, The Logic of Scientific Discovery. New York: Routledge, 2005

[8] H. P. Soetjipto, "Pengujian Validitas Konstruk Kriteria Kecanduan Internet," J. Psikol., vol. 32, no. 2, pp. 74-91, 2005.

[9] M. Mulawarman and A. D. Nurfitri, "Perilaku Pengguna Media 
Sosial beserta Implikasinya Ditinjau dari Perspektif Psikologi Sosial Terapan," Bul. Psikol., vol. 25, no. 1, pp. 36-44, 2017

[10] K. S. Young, "Psychology of Computer Use: XL. Addictive Use of the Internet: A Case that Breaks the Stereotype," Psychol. Rep., vol. 79, no. 3, pp. 899-902, 1996

[11] S. Anggraeni, "Pengaruh Pengetahuan Tentang Dampak Gawai Pada Kesehatan Terhadap Perilaku Penggunaan Gawai Pada Siswa SDN Kebun Bunga 6 Banjarmasin," Faletehan Heal. J., vol. 6, no. 2, pp. 64-68, 2019.

[12] A. N. Utami, "Dampak Negatif Adiksi Penggunaan Smartphone Terhadap Aspek-Aspek Akademik Personal Remaja," Perspekt. Ilmu Pendidik., vol. 33, no. 1, pp. 1-14, 2019

[13] A. Ramadhan and F. Agung, "Hubungan Tingkat Kecanduan Gawai dengan Gangguan Emosi dan Perilaku Remaja Usia 11-12 Tahun," J. Kedokt. Diponogoro, vol. 6, no. 2, 2017.

[14] D. Syahyudin, "Pengaruh Gawai Terhadap Pola Interaksi Sosia dan Komunikasi Siswa," Gunahumas, vol. 2, no. 1, pp. 272-282, 2019.

[15] W. Rahardjo, N. Qomariyah, I. Andriani, M. Hermita, and F. N. Zanah, "Adiksi Media Sosial pada Remaja Pengguna Instagram dan WhatsApp: Memahami Peran Need Fulfillment dan Social Media Engagement," J. Psikol. Sos., vol. 18, no. 1, pp. 5-16, 2020

[16] I. A. M. Sifa and D. R. Sawitri, "Hubungan Regulasi Diri dengan Adiksi Media Sosial Instagram pada Siswa SMK Jayawisata Semarang," J. Empati, vol. 7, no. 2, pp. 294-301, 2018.

[17] S. F. Soliha, "Tingkat ketergantungan pengguna media sosial dan kecemasan sosial," Interak. J. Ilmu Komun., vol. 4, no. 1, pp. 110, 2015.

[18] J. Han, M. Kamber, and J. Pei, Data Mining: Concepts and Techniques (3rd Edition), vol. 10. Waltham, USA, 2012.
[19] K. S. Young, Clinical Assessment of Internet-Addicted Clients. Wiley Online Library, 2011

[20] A. Nursikuwagus, E. Hikmawati, U. N. Wisesty, W. Munggana, and D. Mahayana, "Kajian Saintifik Fenomena Adiksi Gawai dan Media Sosial di Indonesia," J. Teknol. dan Inf., vol. 10, no. 1, pp. 25-39, 2020, doi: 10.34010/jati.v10i1.

[21] I. G. P. N. A. Santika, "Hubungan Indeks Massa Tubuh (IMT) dan Umur Terhadap Daya Tahan Umum (Kardiovaskuler) Mahasiswa Putra Semester II Kelas A Fakultas Pendidikan Olahraga dan Kesehatan IKIP PGRI Bali Tahun 2014,” $J$. Pendidik. Kesehat. rekreasi, vol. 1, no. 1, pp. 42-47, 2015.

[22] W. Susanti and A. Ambiya, "Analisis Korespondensi Hubungan Strategi Pembelajaran dengan Hasil Belajar Mahasiswa," SEMINASTIKA, vol. 1, no. 1, pp. 209-213, 2018.

[23] B. W. Yap, K. Abd Rani, H. A. Abd Rahman, S. Fong, Z. Khairudin, and N. N. Abdullah, "An application of oversampling, undersampling, bagging and boosting in handling imbalanced datasets," Proc. first Int. Conf. Adv. data Inf. Eng., pp. 13-22, 2014.

[24] B. Illowsky and S. Dean, Introductory Statistics. Open Access Textbooks, 2018

[25] We Are Social, "Digital 2020: Indonesia," 2020. Accessed: Nov. 28, 2020. [Online]. Available: https://datareportal.com/reports/digital-2020-indonesia.

[26] BPS, Pedoman Perhitungan Proyeksi Penduduk dan Angkatan Kerja. Badan Pusat Statistik (BPS) Indonesia, 2010.

[27] M. O. Pratama, D. Harinitha, S. Indriani, B. Denov, and D. Mahayana, "Influence Factors of Social Media and Gawai Addiction of Adolescent in Indonesia," J. Sist. Inf., vol. 16, no. 1, pp. 16-24, 2020. 